\title{
The Thing before Us
}

\section{Agreement and Disagreement between Travis and Ayers}

\author{
Sofia Miguens | ORCID: 0000-0002-8656-2447 \\ Universidade do Porto, Porto, Portugal \\ Naomi Osorio-Kupferblum | ORCID: 0000-0003-2399-7002 \\ Universität Wien, Vienna, Austria \\ naomi.osorio@univie.ac.at
}

\begin{abstract}
In this article the authors identify and analyse points of agreement and disagreement between Michael Ayers and Charles Travis, starting from their views on 'things before us. The authors then try to spell out what separates these philosophers in matters concerning perception, knowledge and language. In spite of their both being selfprofessed realists, equally critical of conceptualism and representationalism, Ayers' empiricism and Travis' anti-empiricism lead them to different positions in these three areas. It is shown that in the case of Ayers they hinge on "ordinary" objects and a KK principle (knowledge that and how we know), whereas in the case of Travis they are articulated around occasion-sensitivity and anti-psychologism.
\end{abstract}

\section{Keywords}

Ayers and Travis - perception - knowledge and language - disjunctivism about perception - disjunctivism about knowledge - realism and empiricism

There is a thing before us. This object - a pig, a dog, a tree, or Sid - the way it is, independently of our thought, in and of itself, as it were, is a crucial element in both Michael Ayers' and Charles Travis' philosophies. It is, thereby, where their views come together, albeit from opposing directions. Our fascination with how different a role particular, real-worldly objects play in their realist, 
anti-conceptualist explanations of knowledge, perception, thought, judgment and language (Ayers 2019, Travis 2021) prompted this juxtaposition. The point of the exercise is to shed light on a number of aspects of their views, in particular where there have been misapprehensions. It will also be an opportunity to contrast their very different ontological commitments.

The thing before us means something very different for Ayers, the empiricist, and for Travis, the anti-empiricist. We thus begin with what each of them means by 'things' and end with issues of realism and idealism. In between we compare some of their views on perception and judgment, knowledge, and language.

There are words Ayers and Travis both use, but with very different meanings. 'Things' is the first we discuss, and the issues go far beyond terminology. Things, for Ayers, are the real-worldly, macroscopic, "ordinary" objects (res indeed sōmata) that surround us and that we, too, belong to. They play a primordial role in his epistemology. His explanation of what knowledge is and how we come to possess it, starts from our contact with our environment in which discrete objects, including ourselves, stand out. (Ayers 2005, 2019) Such things cause thought. Not just individual thoughts when we perceive them, but ultimately all thought - there is no thought without acquaintance with things. Even thought in areas seemingly far remote from macroscopic objects, for instance in particle physics or in mathematics, builds on our acquaintance with things in the primary sense. It is perception of things that provides infants with the elements of thought in three essential ways.

First, the macroscopic objects that surround us - the things we are most concerned with in everyday life - are naturally discrete and unitary; and they are presented to us (and all other sentient animals) like this in perception. Ayers' stressing this point has two motivations. Against the sceptic, he contends that there is no theory or inference involved in our belief that we perceive material objects - we perceive them, because they are there and thus "given". Against the conceptualist (Quine as much as P. F. Strawson), he stresses that material objects don't need concepts for their individuation. Instead, their being individuals enables us to develop conceptual thought. (Ayers 2019) Conversely, properties, events, and processes - called 'modes', following tradition - are what things are like, what they do or undergo, and do not naturally come as individuals. (Ayers 1991b) We owe the logical structure of 
thought, when it is propositional, to the things we are acquainted with. This is reflected in the subject-predicate structure of natural language, which we find in languages around the globe. When we use nouns or other forms of nominalisation to refer to what are not physical objects, but 'reified' entities from other ontological categories, we follow the grammatical and logical pattern of thought and talk about things that need no reification because they are 'res'. (Ayers 1991a, 2005, 2019)

Secondly, the ontology of material objects is not just relevant with respect to their individuation, and thereby their recurrent identifiability; how they come about and cease to exist is also at the foundation of manifest similarities based on which we classify objects. This is particularly evident in biological objects, all of them (all of us, rather) off-springs by procreation, whose belonging to natural kinds teaches us much of the taxonomy we use for them. So, when we classify them under names of species and genera, this classification is bottomup, as it were, learnt from the objects so classified. Instead, the classification, identity and differentiation of properties, events, and processes follows conceptual delimitations and is thus top-down. (Ayers 1991a,b, 2005)

Third, and no less importantly, perception of things teaches us about causality. Perception is itself a causal relation between us and its objects, and in perceiving them, we know that we are causally related to them. This is because we can, by our actions, change the way we perceive them. Changing our position vis-à-vis an object changes what we perceive of it, and in particular moving things around makes us aware of the causal impact we have on them and they on us. Crucially, this is also what brings about and explains the integration of our senses. Our perception of the world is multi-sensorial thanks to the independent existence of discrete objects which we can causally relate to. (Ayers 2019) So, the abilities we have - physical as well as mental - allow us to move about in a world filled with macroscopic objects. Travis sometimes calls such objects "collidables", a term that highlights the causal role of material objects Ayers stresses.

So, things are at the foundation of Ayers' epistemology and come first in many explanations he gives. For Travis, things are likewise very important, but in a totally different way.

What Travis means by 'things' is not that straightforward. To start with, spatiotemporal particulars, 'collidables', are not the sole, or the main focus in his talk of 'things'. This is clear from his use of expressions such as 'the way things are' or 'things being thus and so', often followed by the comment 'by that I mean things in the catholic sense, so you do not ask 'which things?". (Travis 2013, Travis 2021) In this use, 'things' is a mass term; it indicates indeterminately, it does not allow for quantification. So, in spite of their importance for 
perception and knowledge, macroscopic worldly objects, i.e. particulars like this bottle or this computer, are not the paradigms of Travis' things. Indeed, they are not necessarily paradigmatic of what he means by 'objects' either, especially when writing about thoughts and ontology. This is also clear when he speaks of concepts and objects, from a Fregean viewpoint on thoughts. (Travis 2013, Travis 2021) Being an 'object' is a matter of identity and recurrent identifiability, whatever the object is, to be contrasted with concepts, characterized by the fact that the question whether something falls under them makes sense. So, if we read 'things' as 'objects', there is no paradigm. They can be whatever they turn out to be in ongoing thought-world relations, provided that identity stands. Objects in Travis' sense are introduced in terms of their logical role only.

The first role of 'things' (again qua mass term) is to bear on the truth or falsity of a thought. (Travis 2021) This is because a thought makes truth turn on the way things are. Note, however, that thoughts in the countable sense (sense number 1 ), such as Sid smokes, $7+5=12$ or The leaves are green, are to be distinguished from 'thought', qua mass term, meaning that which thinkers do, the general phenomenon of thinking (sense number 2). 'Thought' can also refer to objects of thought in general (sense number 3 ) - the totality of things that can be thought. Thoughts in the countable sense are general and independent of, but accessible to, individual thinkers. It takes a thinker's occasionsensitive judgment to relate a 'historical' (i.e. particular) pig, Sid, or any other real-worldly way things are to the conceptual generality of a thought (a way for things to be, sense 1). So, a thinker's taking things to be thus-and-so involves both ways for things to $b e$, i.e. generalities, and the way things are, i.e. the particular or 'historical'. Generalities are involved in Travis' story as soon as there is such 'taking to be' by a thinker. They admit being instanced. Ways things are, are not 'instanced': they simply are. Thoughts in sense 1 suppose representingas by a thinker; they are abstractions from utterances made by thinkers on a particular occasion faced with and in light of the way things are, in taking them to be a certain way. An important note is due here: abstraction, for Travis, is not a process, something thinkers do in their heads, instead it is a separating out of one thing from another. You have people representing things to one another, talking, for example. What needs separating out is that on which the truth and falsity of what they think and say depends - that which has the lawlike behaviour that matters for logic. And for that you need an abstract model, that is, one needs to find the parameters, the variables, that the laws will be sensitive to. So, this is abstraction in the sense of e.g. a scientific model, not in the empiricist sense of a psychological process of, as it were, extracting concepts. 
Several points about thought and perception here are relevant for the comparison with Ayers. Things in the (catholic) sense of the way things are, are the capstone in Travis' account of human thinking and action. But there is no simple way to identify his use of 'things' with particulars or to move on from there directly to an ontology of substances and modes. Also, perception is simply awareness of one's surroundings, or of one's body; taking things to be a certain way is done by the thinker him/herself - we'll say more about perception below. Travis' fundamental claim regarding things and thought (mass term) is a second point here, namely that 'the world does not auto-articulate', or put differently, that reality is non-conceptual. Thoughts (countable sense) require thinkers. The third point is that there is a categorical, ontological distinction between the conceptual (ways for things to be) and the non-conceptual (ways things are, the particular, the historical) built into Travis' talk of things. (Travis 2013, Travis 2021)

The term 'facts' is often used to speak of how things are, and the idea that 'facts' are true thoughts is usually attributed to Frege. Travis would prefer to formulate things differently: a fact is the instancing of a way for things to be by the way things are; wherever there is a true thought, there is a fact. If the thought is true, then the fact is of things being the way the thought represents them. So, if the thought is that the floor is wet, then the fact consists in the floor being wet. Fact is a circumstance, an Umstand.

Travis and Ayers agree that generality plays an important role in facts while it plays none in the way things are. In speaking of thoughts being true, and thereby bringing in truth, we are, according to Travis, already dealing with the business of logic. Logic is not concerned with the capacities of thinkers involved in particular thinkings: it concerns primarily truth transmission between given decompositions of thoughts. (Travis 2021) Still, of course there is no truth to transmit without the phenomena of truth-yielding, and correlatively, of representing-as. This is where thinkers and perception come in. Truth transmission is to be clearly distinguished from truth-yielding. Truth-yielding is a relation starting from something like this object in front of me, which is neither true nor false. (Travis 2021) A relation is truth-yielding if it holds between this first relatum, which is just not true or false, and, as a second relatum, something that can be either true or false, and the second is in fact true. So in our example: there's an object in front of me, there is a thought that there is a computer on my desk, there is a relation between the two, and the second is true. The presence of this before my eyes may then mean that there is a computer before my eyes; it is for that to be what the object of my perception is. 


\section{Perception and Judgment}

Since both Ayers and Travis vehemently oppose views according to which "veridical" perception, illusion and hallucination possess a common factor, they could count as disjunctivists regarding perception. However, they oppose such views for very different reasons.

One way Travis argues against the postulation of a common factor is grammatical (in a Wittgensteinian sense). Predicates have certain domains of application. Thus "red" is a predicate that applies to environmentally situated objects. If we predicated "red" of a hallucination, we would have to invent a new way to evaluate statements that predicate 'red' of something for their truth or falsity. So, the common-factor argument fails. (Travis 2013)

Ayers, by contrast, founds his protest against the common-factor view on perception rather than grammatical observations. In the classical direct-realist manner, he regards perception as by definition of one's environment - perception is our direct cognitive contact with something in our surrounding. Therefore, hallucination is simply a different kind of event all together. But this is only one part of his argument. He has two more elements to add, both reflecting his empiricism: First, when we perceive, we know that and how we perceive the object. This second-order knowledge is missing in hallucination. Second, perception is multi-sensorial (see 1. above). Our senses are integrated and jointly put us in touch with the object of perception. So, while people sometimes hallucinate as they are falling asleep or waking up, or when feverish, this is usually detected to be hallucination sooner or later. Illusions, by contrast, are harder to recognise in the act, but - like most cases of hallucination - they are usually of one sense only and can therefore be corrected by the other senses. Ayers stresses that the concepts of illusion and hallucination presuppose perception. If our senses didn't deliver accurate information about the world most of the time, the mere concept of their failing in illusion and hallucination would not make sense. (Ayers 2019)

This is close to how Travis, following J.M. Hinton, articulates the rejection of the common-factor view for perception in terms of a disjunction. (Travis 2013) Either you are perceiving or you are undergoing an illusion. There is not a something (say, content or experience) which is common to both. In fact, postulating a common factor would lead us out of the world, into something mind-dependent. But that is an unwarranted move. A case of perception is simply of a very different sort than a case of illusion. This then has the consequence that the relevant notion of highest common factor can't make sense. No such notion is available. 
A slightly different point is to be formulated for disjunctivism about knowledge (see below).

Despite their different focuses, Travis and Ayers are brothers in arms not only against the common-factor view, but also against representationalism, in particular as propounded by one prominent self-proclaimed disjunctivist, McDowell. Both specifically oppose his conceptualism regarding perception, i.e. the idea that perceiving is a conceptual taking-to-be. (Travis 2013) These discussions are therefore a good place to compare their views on judgment.

One important difference between them is the explanatory direction. While Ayers takes us from the world via perception to knowledge and only then to judgment, Travis, like McDowell, goes from judgment to world via perception. So, both McDowell and Travis start from thought, not from perception. But according to McDowell, unlike both Ayers and Travis, perception is representational. The old McDowell of Mind and World (1996) had perception of the world and conceptual thought in one propositional package. The new McDowell (2009, 2013) drops propositionality, but still thinks perception has representational content - he now speaks of 'intuitional content', which is connected with apperception. However, the non-propositional turn in McDowell's philosophy only means (at least Travis thinks it can only mean) that he has separated propositional content from the form of a proposition: Instead of saying, 'Sid ate the whole thing' we have something like 'the eating of the whole thing by Sid'. We then just need one predicate to restore propositional form - something like 'is the case'. Anyway, intuitional content becomes propositional when our conceptual capacities are exercised and a thought is formed. Perceiving is a taking-to-be, which then is (or is not) endorsed by judgment. This means that perceivings (seemings) are claim-like, i.e. they are claims-which-are-not yetjudgments. This is how perception is concept-laden for McDowell.

Both Travis and Ayers reject this. According to Travis, perception simply puts the world in view; it affords awareness of what is before us, it puts opportunities on offer. (Travis 2013) Thought (sense 2 as mass term) is a response to this; only in thought can there be representing, as well as truth and falsity. Representation always requires commitment of some sort or other; thus, representation can only be representing-as done by a thinker. Representing-as is, for Travis, a three-party affair: there is (i) the representer, a thinker representingas (ii) a stretch of the non-conceptual (what is represented-as, the way things are) as (iii) a way for something to be (so involving the conceptual, i.e. 'ways for things to be'). There is no representation proper short of this three-party affair; for there to be representation, there has to be a reaching from the conceptual ('ways for things to be') to the non-conceptual (the 'ways things are'). This is the work of judgment and thus the work of a thinker, not of the senses. The senses are, in the Austinian metaphor he favours, silent. (Travis 2013) 
Ayers agrees with some of this. He opposes sense data theories as vehemently as Travis and Sellars before him (Ayers 1991a), and, in fact, any sort of atomistic view of perception. For the perceiver, when Ayers discusses "the senses", he usually stresses that perception is multi-modal; and for the perceived, he stresses that we don't perceive isolated properties by our various senses that have to be conceptually united into one thing. Instead, it's (all of) me - not my senses - that perceives the (whole) object - not some of its properties. Perceiving our surroundings means being in direct cognitive contact with them. Perception thereby yields awareness of our surroundings and of ourselves in them, but all this is a sort of "knowledge by acquaintance" requiring no concepts. Perception is pre-conceptual. (Ayers 2019) Judgment of a propositional type, i.e. of an object or event as being of some sort or as having some property, usually occurs only when prompted, for instance because we want to communicate what we perceive. The thoughts we form in doing so are strongly language-reliant. (Ayers 2005) Needless to say, they are entirely personal. What makes them shareable is how we acquire language, which is, in turn, closely linked to inhabiting a shared world (see below).

In summary, Travis starts from the thought and lets us judge - in view of a particular pig - whether that thought is true of this pig. Ayers starts from the pig, lets us see what the pig is like, and - if prompted - judge that the pig is $F$ ( $F$ being a specific property). McDowell has us see the pig and, inherent in the perceiving there is already an intuitional content, a claim anchoring the judgement that the pig is $F$. Let's now see what impact this difference in explanatory direction has on Ayers' and Travis' accounts of knowledge.

\section{$3 \quad$ Knowledge}

That perception is an essential part of Ayers' empiricist philosophy, particularly of his account of knowledge, shows in his emphasis on the notion of 'evidence'. He uses it not as distinct from proof, as Travis does, but in its primary sense derived from Latin videre: being evident is (roughly) being 'in plain sight' - we simply see it, not just literally but also by figuratively 'seeing' or understanding. (Ayers 2019)

Ayers' epistemology (Ayers 1991a, 2019) is much indebted to the tradition from Plato, and particularly Aristotle, to Locke which marked a sharp distinction of kind between knowledge and belief. He draws a parallel distinction between whether there is direct, or at least traceable, contact with the object of knowledge, or not. However, his own notions of knowledge and belief are considerably more inclusive than those of the tradition, and thus much more in line with common sense. Belief, for Ayers, simply covers everything we think 
with assent, whether such thought is propositional in structure or not, and whether what we believe is known in the form of primary knowledge, or secondary knowledge (see below), or not known at all but only assumed. This last sort of belief, the object of which is not known, i.e. what was traditionally considered belief (henceforth belief $f_{\mathrm{T}}$, to mark the difference), admits of varying degrees of probability in a way knowledge does not. In some regrettable cases, belief $_{\mathrm{T}}$ can even float free of knowledge (and have a probability of, or near, nil). Knowledge, by contrast, is certain.

Ayers' notion of knowledge is also more inclusive than that of Plato, Aristotle or Locke. In addition to primary knowledge, which meets the rigorous traditional requirements, he gives an account of secondary knowledge, which builds on primary knowledge but has slightly less demanding criteria to comply with. Perception makes two essential contributions to the two-fold account. First, it provides direct cognitive contact with what we perceive, and second, through cognitive proprioception, as it were, of ourselves as perceiving, i.e. as standing in such direct contact with what we perceive, it yields knowledge that and how we know (also known as a "KK account"). Primary knowledge simply consists of both. Seeing a pig on the sofa (as in Travis' example) means that I am in direct cognitive contact with the pig and the sofa, and I am also aware of being so related and seeing them; I therefore know not just that a pig is on the sofa, but also how I know that.

There are however cases in which only one of the two elements is present, while the other is missing, i.e. where we are only either in direct cognitive contact with something, or know how we know. These are thereby importantly different from beliefs $\mathrm{T}_{\mathrm{T}}$. And they still constitute much of what we habitually consider knowledge in everyday life - when we know that a goat was here because we see its droppings, know that $\mathrm{C}_{6} \mathrm{H}_{12} \mathrm{O}_{6}$ is the chemical formula of sugar because we remember it from school without remembering why, and know that $a^{2}+b^{2}=c^{2}$ in a right-angled triangle although we've forgotten the proof and can't reconstruct it. In all these cases, one of the two elements required for primary knowledge is missing, however, the other one is still there and links up to primary knowledge. Therefore, Ayers calls knowledge in this wider sense 'secondary knowledge'.

Secondary knowledge is impossible without some primary knowledge

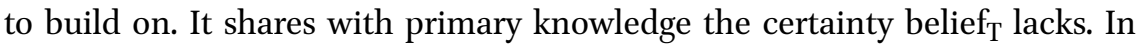
beliefs $_{T}$ we lack both direct cognitive contact with the relevant facts and an uninterrupted intelligible connection to them. Thus, taking something on trust implies that we don't know it from our own experience, nor do we know anything from which the content of that belief would immediately follow. Cases of secondary knowledge, by contrast, are not cases where we take on trust what 
we perhaps shouldn't have, or make a (more or less) clever guess. Neither are they cases such as those Locke warns us of in his ECHU IV.xx., where we may get our probabilities wrong. Although secondary knowledge is less immediately evident to us than primary knowledge, it is still certain.

Ayers stresses the difference between the certainty of knowledge, on the one hand, and its defeasibility, on the other. Knowledge is certain in the sense that it does not admit of probability. Probability, when neither o nor 1, implies that there is some - however small - epistemic possibility that a belief may turn out to be mistaken. Such epistemic possibility for things not to be as we think, is simply not there in the case of knowledge: what we know is evident to us, and we know that and how we know. There is no room for doubt. If there were, what we have would not be knowledge but merely belief . No additional investigation or information can increase the certainty of what we know (probability cannot go above 1, if we consider 'probability 1' still probability, as mathematicians do), it can only corroborate our knowledge. If it did and if it thereby ruled out any remaining possibility that things are not as we think, it

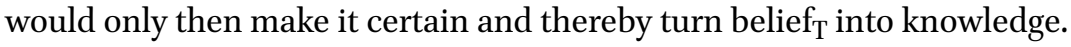

But the certainty of knowledge is independent of its defeasibility. Knowledge, on Ayers' account, is a personal affair: we each have to do our own knowing, as it were. Pace Travis (2021), this means that knowledge depends on our physical and intellectual capabilities. As our capabilities are fallible, this means that all our knowledge is in principle defeasible. Any piece of knowledge we possess can "theoretically", one might say, turn out to be proved wrong. But this doesn't mean that we can't usually trust our capabilities. Remember that we can only make sense of them failing because they usually "work". So their impairment (if any) must first be brought up as a serious epistemic possibility in order to undermine a piece of knowledge, and the burden for raising such doubt is squarely on the doubter.

Such an epistemic possibility of error, however, must be both novel and plausible in order to be a reason for doubt. If it were not novel, i.e. due to new information or a new perspective, that would either mean that we hadn't done what was needed for obtaining knowledge and thus didn't know in the first place, or that it wasn't relevant. If it wasn't relevant before, something new must have occurred to make it relevant now. It must, moreover, be plausible in order to introduce an epistemic possibility of error. Evil demons and mad scientists fail the test on this account. So, if I know a pig when I see one, and I see a pig on the sofa, I know that there is a pig on the sofa and I also know how I know that, viz. because I see it before me. It would take new information, e.g. that Benno has been playing around with holograms, to introduce the epistemic possibility that I may be seeing a hologram rather than an actual 
pig on the sofa. While no such new option, distinct of and plausible enough to potentially supersede my knowledge, arises, I know that there is a pig on the sofa. The fact that my senses can in principle fail, or that I could in principle be seeing a hologram, is not enough to defeat my current knowledge.

To sum up, because all knowledge we have depends on our - fallible human abilities, it is in principle defeasible. Yet, this does not make it any less certain while there is no plausible epistemic reason to doubt it.

Travis is not primarily an epistemologist; his views on knowledge arise from his positions on perception and language. A disjunctivist about knowledge, Travis sees no common factor in the two truth-serving elements of evidence and proof. This is a point he regards as blurred in Ayers' distinction between primary and secondary knowledge. (Travis 2021) For Travis, evidence supports belief and never yields knowledge, only proof does. The touchstone of disjunctivism about knowledge is then that when one knows, one has nothing less than proof. Knowing does not differ from believing as a matter of degree. Proof rules out absolutely things being other than as proved. This way of thinking of knowledge comes in the line of Oxford realists like Cook Wilson and especially Austin. Austin's pig, which Travis often recruits for his examples, is not just more evidence. Evidence is not all that we ever have. Sometimes we know: in a situation where there is a pig on the carpet and we see it, seeing the pig on the carpet is proof that there is a pig on the carpet, not evidence. The pig's (historical) presence on the carpet rules out absolutely things being otherwise. That the viewer has not swallowed some hallucinogenic substance is not part of that proof. (Travis 2021) It does not provide weaker or stronger evidence for the pig's being there - this is a crucial point in Travis' argument. It might very well be that a viewer of this scene had in fact just taken some hallucinogenic substance. It might be that he/she had not. But that does not mean that there is no proof when the pig is on the carpet in front of the viewer. Nor that one has to know that the viewer has not taken a hallucinogenic drug in order for there to be proof. This is Travis' particular way of spelling out the 'asymmetry' between good and bad cases involved in knowledge. It bears on how one conceives of defeasibility, as we explain below.

Coming from this perspective, Travis is critical of Ayers' distinction between primary and secondary knowledge. He thinks that when someone puts forward such a distinction, there is room for suspicion that they mean that there is first and second-class knowledge. He thinks Ayers draws the distinction from perception's phenomenology and thinks that phenomenology has no such weight (maybe they are using 'phenomenology' in different senses).

So, Travis takes up Cook Wilson's view of knowledge as proof, as it may be found in mathematics and then extended. Here, too, Ayers moves in the 
opposite direction: knowledge by perception is paradigmatic primary knowledge, and mathematical knowledge modelled on it - we know a mathematical truth because we grasp a mathematical fact, and we know how we know it because we understand the mathematical proof. In perception, Ayers thinks, the notion of proof does not apply. Instead, primary knowledge makes things evident in a way that no proof is required or could, often enough, even be given - barring looking again. Note that what might count as additional proof in other accounts - e.g. touching in addition to looking - is neither necessary nor easily available to Ayers because of his multi-sensorial view of perception. Moreover, knowledge is not always propositional "knowledge that"; it is very often knowledge sans modification where the idea of a proof simply doesn't arise (compare: How would you prove what a strawberry tastes like?). Primary knowledge of both the propositional and the non-propositional sort is therefore certain.

So how can knowledge be defeated on Travis' account? Travis' views on defeasibility can only be fully understood in connection with his views on occasion-sensitivity (see next section). They also go together with the endorsement of the Cook Wilsonian view. Some main aspects of this are the following. First, one point of Travis' criticism of Ayers' distinction between primary and secondary knowledge is that Ayers' paradigm cases of secondary knowledge would not be knowledge at all in the Cook Wilsonian tradition. Ayers insists that all knowledge is defeasible. Travis thinks this can only be said if one does not take seriously the difference between evidence and proof as the Cook Wilsonian tradition does.

Second, Travis insists that the discussion of defeasibility should be framed in terms of the objects of a capacity, not the (psychological) workings of that capacity - this is something McDowell is absolutely right about, Travis thinks (for an analysis of his confrontation with Tyler Burge see Travis 2013). Yet McDowell forgets the role of language. (Travis 2021) Claims to know involve conditions for meaning and these have to be considered as well in order to fully explain defeasibility. Epistemic status is circumstance-dependent in what regards both truth and proof. Travis brings his context-sensitivity views on language to bear on both.

Language (natural language) is an area of some agreement between Ayers and Travis. Unlike Ayers, Travis is (or, at least, was once) primarily a philosopher of language. His occasion-sensitivity approach, sometimes called 'contextualism', 
or 'radical contextualism', in fact underlies all his other positions (Travis 2017 for a recent formulation), including his distinction between language and thought. (It should be noted that everything we have said above about e.g. generalities and the particular case, objects and concepts, was formulated in terms of thought, not language; 'thought' meaning here the object of thinking, sense number 3 above, and not the (historical) phenomenon of thinking.). It also underlies his views on the multiple decomposability of thoughts. Despite the Fregean core of his view, Travis takes natural language much more seriously than Frege did. We will try to summarize the main points of his view briefly.

Travis stresses that natural language sentences themselves don't represent, or, to put it graphically, sentences don't think, they don't speak; as we have said above, only thinkers represent-as, only thinkers think or speak. The business of natural language sentences is thought expression: they are a means for thinkers to express thoughts. (Travis 2017) Semanticists usually understand meaning in terms of truth conditions. Travis certainly proposes to understand meaning in terms of truth. But he doesn't think sentence meanings fix truth conditions independently of their use by thinkers/speakers in uttering them on particular occasions. This idea about truth and occasion goes beyond most formulations of contextualism qua modulation of meaning for elements of sentences such as indexicals or particular predicates (e.g. 'green' in 'The leaves are green'). As Travis would put it, what could make the words 'the leaves are green' true other than the presumed fact that the leaves are green, is the fact that the leaves counted as green on the occasion of that speaking. Stress is on the work of thinkers in 'what counts as'. (Travis 2017) Since what sometimes counts as green may not do so at other times, there may still be something to make the words 'The leaves are green' false, namely that on the occasion of their speaking those leaves did not count as green. The sentence itself does not fix an invariant way for leaves to be green. One main point of occasionsensitivity is to get clear about the respective role meanings and the world have in fixing truth conditions. What words mean plays a role in fixing when they would be true, yet not an exhaustive role: word meaning leaves room for variation in truth conditions from one speaking to another, from one worldly situation to another.

All these theses about natural language go together with the idea that thought is social - a Wittgensteinian point pervasive in Travis' work (Travis 2013, Travis 2021); it is also one which withdraws philosophy of mind and language from the domain of subjective Vorstellungen (in Frege's sense from Der Gedanke or Über Sinn und Bedeutung, contrasting the subjectivity of Vorstellungen with the objectivity (shareability) of Sinn and Bedeutung). This 
is the ground for a strict separation between the logical and the psychological, which is as crucial for Travis, as he thinks it is for Frege and Wittgenstein, too.

Ayers shares some of Travis' views on language. As a pupil of John Wisdom, an important early proponent of Wittgenstein's thoughts, he agrees with Travis concerning the occasion-sensitivity of linguistic meaning and likewise on the crucial importance of what something counts as for the speaker. Words don't always come easy to a speaker and which words are the 'right' ones to convey a thought is highly dependent on the occasion. So, there is little open disagreement with respect to the social aspects of language and also concerning its role as a tool for gaining important insights. (Ayers 1991a)

Where Ayers' views differ strongly from Travis' is in the connection between language and thought. As thought is entirely personal for Ayers, the interpersonal aspect of language must have its foundation elsewhere. For Ayers, it is rooted in the world because we acquire language by hearing other people speak about the world, a process greatly facilitated not just by the fact that we perceivers have similar access to the world via perception, but also by the mind-independent structure of the world reflected in the structure of language. (Ayers 1991a, 2005; see section 1 above) Likewise, some of what Travis calls 'generalities' - natural kinds, essential properties - are ultimately rooted in the world; they are knowable not only to us, but to all sorts of animals.

Note, however, that thoughts for Ayers differ from Travis' not only in being individual mental acts, but also because they are often not propositional. Propositionality comes into play mainly when we want to communicate our thoughts, i.e. on a language level. Language is therefore an intellectual tool of great importance for Ayers. (Ayers 1991a, 2005) Travis, by contrast, would attribute no such features to thoughts.

Let us now sum up these contrasts and points of agreement with the help of some "isms". We have called both Ayers and Travis 'realists', and this is also how they think of themselves. But what does this mean? In principle, it means giving the world its due in an account of thought, knowledge and perception. Yet, they diverge in how they do it: Ayers wants to ground a new empiricism, Travis is very critical of empiricism. One could say that Travis' philosophy targets an empiricism of the idealist kind (think Hume, for instance, or better, Quine). That is a point on which Ayers fully concurs. In fact, the danger of sliding into idealism is something philosophers near Ayers quickly learn to dread, and 
he doesn't tire to point out that Hume as much as Quine (and other empiricists between, before (e.g. Burthogge) and after them) sever the connection between world and mind. Ayers' own empiricism is thoroughly realist - one might even say that his realism is empiricist. There is no place in his philosophy where a wedge could be driven between the world and the mind. So, he poses a challenge to Travis' rationalism different from most.

In turn, Ayers is very critical of rationalism. However, his arguments target rationalism in its (Neo-)Kantian conceptualist guise (as e.g. McDowell). As a Wittgensteinian, Travis is certainly not a rationalist of any traditional kind. His "rationalism" is of the Fregean type and he concurs with Ayers in his criticism of conceptualism. He blames conceptualists for thinking that the world 'auto-articulates', whereas he himself demands that the logical and the conceptual should be kept strictly apart from the psychological, stressing that only the former is the business of philosophy. He thereby poses a challenge to Ayers' empiricism different from most. Still, for a realist empiricist like Ayers, as for Aristotle, Hobbes or Locke before him, perception is simply constitutive of his entire philosophy. This means that some of what Travis considers 'the psychological' is in fact an essential part of Ayers' philosophy. Also, Ayers does think that the world 'auto-articulates' to some extent, in the sense that its metaphysical structure brings about the deep structure of our thinking. Such sharp contrast between the two regarding the role of perception in philosophy is also reflected in their distinct ontological stances, as revealed by their take on 'things'. Even if their views come together again in the Wittgensteinian stress on the social aspects of language, Ayers' focus is on language acquisition, whereas Travis' focus is on generality and context-sensitivity (of language but also of thought itself), again reflecting the contrast.

We have tried to show the many places where Ayers' and Travis' philosophies meet, and to highlight the opposing directions from which they do so. Their views are surely at opposite ends of realism. It is this opposition that makes the challenges they put to each other so relevant.

\section{Acknowledgments}

This article arose from the presentation we made at the Book Symposium on Michael Ayers' Knowing and Seeing at Universität Wien in February 2020. The presentation followed Charles Travis' comments on Ayers and tried to open a dialogue between the two authors. The article has an unusual shape: in analysing the philosophies of Michael Ayers and Charles Travis we chose not to quote, but to simply formulate their positions. This methodological choice was 
made because we relied not only on their written work, but had the direct help of the two authors. We are very thankful to Michael Ayers and Charles Travis for having accompanied us throughout the process of writing this article. Naturally, any mistake in the formulation of their positions should be attributed to us and not to them. We'd also like to thank Mira Magdalena Sickinger and a referee for helpful comments.

\section{References}

Ayers, Michael 1991a. Locke. Epistemology and Ontology. London/New York: Routledge. Ayers, Michael 1991b. "Substance: Prolegomena to a Realist Theory of Identity." The Journal of Philosophy 88 (2), 69-9o.

Ayers, Michael 2005. "Ordinary Objects, Ordinary Language, and Identity." The Monist $88(4), 534-570$.

Ayers, Michael 2019. Knowing and Seeing. Groundwork for a New Empiricism. Oxford: Oxford University Press.

McDowell, John 1996. Mind and World. Cambridge, MA: Harvard University Press.

McDowell, John 2009. Having the World in View: Essays on Kant, Hegel, and Sellars. Cambridge, MA: Harvard University Press.

McDowell, John 2013. "Perceptual Experience: Both Relational and Contentful." European Journal of Philosophy 21 (1), 144-157.

Travis, Charles 2013. Perception - Essays after Frege. Oxford: Oxford University Press.

Travis, Charles 2017. "Views of my Fellows Thinking (Counting Thoughts)." dialectica 71 (3), 337-378.

Travis, Charles 2021. Frege - The Pure Business of Being True. Oxford: Oxford University Press.

Travis, Charles (2021). "At Work in the Fields of the True." Grazer Philosophische Studien $98(4), 561-558$. 